\title{
> A Prosa Poética de Kate Chopin: imagens líricas da noite e o descompasso do homem na orquestra de Deus
}

\author{
> Kate Chopin's Prose Poetry: \\ lyrical images of the night and the mismatch \\ of the man in God's orchestra
}

\section{por Rosemary Elza Finatti}

Mestranda no Programa de Pós-Graduação em Estudos Literários pela UNESP Faculdade de Ciências e Letras de Araraquara. Graduada em Letras (Português/Inglês), Licenciatura e Bacharelado, pela mesma instituição. Atualmente é professora de Língua Inglesa na Secretaria Estadual de Educação. Tem experiência na área de Letras, com ênfase em Língua e Literatura Inglesa. Desenvolve pesquisas sobre a vida e obra de Kate Chopin, Estudos Literários e Feminismo. E-mail: rosefinatti@gmail.com. ORCID: 00000002-0605-4013.

\section{Resumo}

A proposta de análise dos contos The Night Came Slowly (1894) e A Reflection (1899) de Kate Chopin considera a perspectiva de Lefebve (1980) de que, embora com estruturas distintas, o discurso da poesia e o discurso da narrativa operam do mesmo modo e são capazes da mesma poesia. Intenciona-se mostrar como a prosa poética de Kate Chopin articula imagens líricas e uma linguagem simbólica para tratar de questões metafísicas e atemporais, assinalando o viés de crítica social da autora. Para tanto, a análise será norteada pelos fundamentos teóricos propostos por Massaud Moisés, Octavio Paz, Jean Y. Tadié, entre outros, pelos aspectos simbólicos apontados por Gaston Bachelard e Mircea Eliade bem como por autores que embasam a crítica literária chopiniana.

Palavras-chave: Prosa poética. Kate Chopin. The Night Came Slowly. A Reflection.

\begin{abstract}
The proposed analysis of Kate Chopin's The Night Came Slowly (1894) and A Reflection (1899) considers Lefebve's (1980) perspective that, although with distinct structures, poetry discourse and narrative operate in the same way and are capable of the same poetry. It is intended to show how the prose poetry of Kate Chopin articulates lyrical images and a symbolic language to address metaphysical and timeless issues, marking the bias of the author's social criticism. Therefore, the analysis will be guided by the theoretical foundations proposed by Massaud Moisés, Octavio Paz, Jean Y. Tadíe, among others, for the symbolic aspects pointed out by Gaston Bachelard and Mircea Eliade as well as by authors who support the Chopin's criticism.
\end{abstract}

Keywords: Prose poetry. Kate Chopin. The Night Came Slowly. A Reflection. 


\section{Considerações sobre a prosa poética}

A prosa poética se caracteriza pela mistura entre dois gêneros literários distintos, porém passíveis de combinação e ressignificação. No intuito de abordar a junção de tais termos, faz-se necessário apontar as peculiaridades da poesia, do poema e da prosa. A palavra poesia origina-se do grego poíesis, e significa a ação de fazer, criar, alguma coisa. ${ }^{1} \mathrm{O}$ conceito de poema, do grego poiema, refere-se ao que se faz. Já a conexão entre poesia e poema implicaria um juízo de valor de que todo poema contém poesia e vice-versa. ${ }^{2}$ Além disso, a estrutura do poema pode ocorrer em versos ou em prosa e a linguagem poética é dotada de uma potência revolucionária por revelar e inventar o mundo, simbolizando um modo de "libertação interior"3. Nesse sentido, a poesia engendra a expressão do eu por meio de uma linguagem metafórica e polissêmica cuja intenção é sugerir, cabendo ao leitor desvendar a pluralidade de significados intrínsecos à sua incompletude. A linguagem poética é nebulosa, complexa e transgressora, uma vez que revela o que está por trás das aparências, libertando a palavra das convenções e da lógica das normas linguísticas.

Por outro lado, a prosa fala em amplidão por meio de uma narrativa que se conclui ao findar da história. Dessa forma, sua "essência é perecer, ou seja, ser "compreendida" - ou seja, ser dissolvida, irremediavelmente destruída, inteiramente substituída pela imagem ou pelo impulso que ela significa de acordo com a convenção da linguagem"4.

Para estabelecer a diferença entre poesia e prosa, Paul Valéry as associa à dança e à caminhada, respectivamente,

O andar, como a prosa, visa a um objeto preciso.

[...] A dança é totalmente diferente. É, sem dúvida, um sistema de atos; mas que têm um fim em si mesmos. Não vão a parte alguma. Se buscam um objeto, é apenas um objeto ideal, um estado, um arrebatamento, um

\footnotetext{
${ }^{1}$ Massaud Moisés, Dicionário de termos literários, 1974, p. 402.

${ }^{2}$ Ibidem, p. 400.

${ }^{3}$ Octavio Paz, O arco e a Lira, 1982, p. 21.

${ }^{4}$ Paul Valéry, Variedades, 2007, p. 164.
} 
fantasma de flor, um extremo de vida, um sorriso - que se forma finalmente no rosto de quem o solicitava ao espaço vazio. ${ }^{5}$

O caminho da prosa busca o entendimento do leitor, permite-se desvendar. Já a poesia, assim como a dança, transcende até mesmo as restrições da linguagem, uma vez que não tem a pretensão de chegar em nenhum lugar, assinalando o viés enigmático da imaginação do poeta.

Por sua vez, Octavio Paz recorre às representações de linearidade da prosa em oposição à circularidade da poesia

Enquanto o poema se apresenta como uma ordem fechada, a prosa tende a se manifestar como uma construção aberta, linear. [...] A figura geométrica que simboliza a prosa é a linha reta: sinuosa, espiralada, ziguezagueante, mas sempre para diante e com uma meta precisa. Daí que os arquétipos da prosa sejam o discurso e a narrativa, a especulação e a história. O poema, pelo contrário, apresenta-se como um círculo ou uma esfera - algo que se fecha sobre si mesmo, universo auto-suficiente [sic] no qual o fim é também um princípio que volta, se repete e se recria. ${ }^{6}$

Embora classificados de maneiras distintas e com peculiaridades próprias, os gêneros literários não são regidos por leis fixas, pois a diferença entre eles não ocorre por meio de oposições brutais - sobretudo entre prosa e poesia e entre música e evocação realista, como convencionalmente se acreditava - mas, sim, por meio de variáveis de funções, funções frequentemente mais sutis do que as da linguagem. ${ }^{7}$ A partir de tais implicações, a locução prosa poética se refere a uma obra em prosa que se deixa permear por soluções poéticas. ${ }^{8}$ Nesse sentido, a prosa poética conserva a estrutura prosaica e a sequência do discurso, imprimindo um olhar lírico sobre o mundo de personagens, em um determinado espaço e tempo, por meio de imagens poéticas associadas aos elementos próprios da poesia, como cadência, aliteração, personificação, comparação, metáfora, entre outros.

\footnotetext{
${ }^{5}$ Ibidem, p. 204.

${ }^{6}$ Octavio Paz O arco e a Lira,1982, p. 83.

${ }^{7}$ Jean Yves Tadié, Le récit poétique, 1978, p. 2.

${ }^{8}$ Massaud Moisés, Dicionário de termos literários, 1974, p. 420.
} 
Assim, a proposta deste artigo é analisar os contos The Night Came Slowly (1894) e A Reflection (1899) de Kate Chopin, mostrando os elementos da narrativa articulados ao lirismo da linguagem e aos aspectos simbólicos presentes nos contos sob a perspectiva apontada por Lefebve de que, embora com estruturas distintas, o discurso da poesia e o discurso da narrativa operam do mesmo modo e são capazes da mesma "poesia". A escolha dos contos justifica-se pela semelhança temática, uma vez que ambos abordam questões metafísicas do homem que, isolado da multidão, contempla a vida sob um ponto de vista crítico e busca transcender os limites da condição humana.

\section{O lirismo da prosa chopiniana}

Kate Chopin (1850-1904), uma das mais renomadas autoras do Realismo estadunidense, vivenciou uma carreira literária extremamente curta, porém bastante profícua, pois seu multiverso ficcional é constituído por contos, romances, poemas, traduções e ensaios críticos. Suas obras não se restringem à temática da cor local, como afirmam muitos críticos, uma vez que abordam temas tabus para a sociedade do século XIX, como o adultério, o preconceito racial e a autoafirmação feminina, demonstrando um fazer literário inovador tanto na questão temática, quanto no tratamento elaborado da forma. Uma das características marcantes da habilidade narrativa da autora é o lirismo da linguagem, representado por imagens poéticas, metáforas, musicalidade e subjetividade, visto que "Suas histórias são uma celebração lírica da vida. Nelas, os sentimentos de um personagem estão associados à 'canções' e 'vozes' naturais ou à imagens de objetos e eventos na natureza"10. É interessante observar que Kate Chopin inicia a sua carreira literária escrevendo poemas. Sua primeira obra literária publicada foi o poema It Might be na revista de Chicago intitulada

\footnotetext{
${ }^{9}$ Maurice J. Lefebve, Estrutura do discurso da poesia e da narrativa, 1980, p. 29.

${ }^{10}$ Bert Bender, Kate Chopin's Lyrical Short Stories, 1974, p. 257, tradução nossa: "Her stories are lyric celebrations of life. In them, a character's feelings are associated with natural "songs" and "voices" or with images of objects and events in nature".
} 
America, em 10 de janeiro de 1889.11 Além disso, o viés artístico e a singularidade da escrita chopiniana são destacados no ensaio crítico da revista The Nation 66 de 1898, o qual enuncia que "Kate Chopin conta uma história como um poeta, e reproduz o espírito de uma paisagem como um pintor"12. As referências literárias que a influenciaram são as obras de Zola, Guy de Maupassant e Walt Whitman, sobretudo porque nada era mais importante para ela do que o esforço para dizer a verdade ${ }^{13}$. Para Kate Chopin, a verdadeira arte pressupõe um entendimento profundo da vida, o que não se pode alcançar a menos que aceitemos que o homem e a natureza constituem um continuum. ${ }^{14}$

\section{Elementos da narrativa no conto The Night Came Slowly}

O conto The Night Came Slowly foi escrito em 24 de julho de 1894 e publicado na revista Moods da Filadélfia, em julho de 1895. Em 1969, o conto foi republicado na obra The Complete Works of Kate Chopin, de Per Seyersted. ${ }^{15}$

Trata-se de um narrador-personagem que, deitado debaixo de uma árvore de bordo, reverencia a natureza e comtempla o anoitecer com admiração.

Os personagens são representados por elementos da natureza e pela humanidade, porém em nenhum momento o narrador os chama pelo nome. É

\footnotetext{
${ }^{11}$ Per Seyersted, A Critical Biography, 1980, p. 50, tradução nossa: "A progressive Chicago magazine called America published "If I Might Be", on January 10, 1889, and this marked Mrs. Chopin's first appearance in print".

${ }^{12}$ Alice H. Petry, Critical Essays on Kate Chopin, 1996, p. 49, tradução nossa: "Kate Chopin tells a history like a poet, and reproduces the spirit of a landscape like a painter".

${ }^{13}$ Bernard Koloski, Awakenings. The Story of the Kate Chopin Revival, 2009, p. 196, tradução nossa: "There is nothing, in her mind, more important than striving to tell the truth. It was she so admired in the French writes she read, Zola and Guy de Maupassant, in particular, and, [...] Walt Whitman, as well".

${ }_{14}$ Per Seyersted, A Critical Biography, 1980, p. 89, tradução nossa: "In her view, true art presupposes an understanding of true life, which again cannot be attained unless we accept that man and nature form a continuum".

${ }^{15}$ Per Seyersted, The Complete Works of Kate Chopin, 1988, p. 1017.
} 
interessante observar que a ausência de nomes evidencia a abrangência temática relacionada à condição humana.

A natureza compõe o espaço do conto e é a partir desse cenário mítico que o enredo se desenvolve.

O tempo da narrativa começa no momento em que o narrador observa o nascer da primeira estrela no céu, marcado pela duração entre o crepúsculo e a noite.

O título evidencia a noite como um elemento fundamental no enredo, sobretudo por delinear a imagem poética que constitui o conto e impulsionar o desenvolvimento da narrativa.

\section{Imagens líricas da noite e a simbologia da natureza}

A noite era inspiradora para Kate Chopin, sendo um dos símbolos centrais de suas obras, principalmente porque são noturnas as cenas de epifania em suas narrativas, bem como por causa dos elementos simbólicos que representam a noite, como a escuridão, a lua e as estrelas, serem recorrentes em seus poemas. ${ }^{16}$

Ao expressar o desinteresse em compreender a complexidade humana, o narrador sente-se atraído pela noite, que, ao contrário do homem e dos livros, lhe traz reconforto e o inspira a divagar, a conhecer a sabedoria dos seres naturais e a se aproximar do divino.

Para explicar a sua preferência pela noite, o narrador estabelece uma comparação entre a expressividade da noite em detrimento do caráter negativo da humanidade. Dessa forma, ele personifica os elementos da natureza dando a eles características humanas: a noite e as estrelas falam, o vento acaricia.

\footnotetext{
${ }^{16}$ Per Seyersted, A Critical Biography, 1980, p.70-71, tradução nossa: "She returned to the night, a central symbol with her, [...]"
} 
Assim, a natureza representa um refúgio, um "lugar privilegiado"17. Este ambiente privilegiado é marcado por imagens poéticas que sugerem harmonia, transcendência e devaneio, cujo campo semântico constitui-se pelos vocábulos maple tree, valley, trees, foliage, maple leaves e katydids.

Além disso, há um paralelismo entre as expressões like the night e the summer night, cuja repetição do substantivo night intensifica a sua importância e acrescenta sentido ao sugerir a expressividade de uma a noite de verão, evocando a imagem de um céu estrelado, no qual cintilam mais estrelas do que em qualquer outra estação.

Carregada de impressões poéticas, a cena da passagem do poente à noite tem o poder de encantar o narrador. Embora anoiteça todos os dias, aquele instante de contemplação lhe traz sensações únicas, sobretudo porque "Esse instante é ungido com uma luz especial: foi consagrado pela poesia, no melhor sentido da palavra consagração"18.

Os substantivos night, star e wind estabelecem combinações sinestésicas ao relacionar noite / estrela com audição e visão e o vento ao tato, aludindo às sensações que os elementos da natureza despertam no narrador, pois a noite e as estrelas expressam aconchego e o vento afaga mais do que o toque humano.

No segundo parágrafo, a aliteração nos advérbios slowly e soflty representa a maneira como a noite chega, trazendo uma escuridão que invade a natureza de forma lenta e agradável, criando uma atmosfera amena e convidativa para o narrador observá-la embaixo de uma árvore. Além disso, a recorrência de verbos no gerúndio simboliza continuidade e marca o ciclo da passagem do dia até a noite, reforçando a ideia da ocorrência incessante do pôr e do nascer do sol.

\footnotetext{
${ }^{17}$ Jean Y. Tadié, Le récit poétique, 1978, p. 4.

${ }^{18}$ Octavio Paz, O arco e a lira, 1982, p. 227.
} 
A repetição do verbo creeping indica o modo progressivo da aproximação da noite que se arrasta pelos vales, e a rima interna entre os verbos creeping e thinking personifica a noite, uma vez que creeping remete à imagem de um animal rastejando que se aproxima sorrateiramente e thinking lhe atribui a qualidade de pensar. Através de tais elementos poéticos, a noite adquire o caráter de protagonista do conto, justamente porque "Transformado em personagem, o espaço tem uma linguagem, uma ação, uma função, e talvez a principal; sua casca abriga a revelação". ${ }^{19}$

Esta revelação se manifesta na medida em que a noite tem muito mais a dizer ao narrador do que os homens e, ao observá-la, ele encontra as respostas que a natureza humana não lhe traz. Dessa maneira, ele se aproxima do sagrado, visto que

A simples contemplação da abóbada celeste é suficiente para desencadear uma experiência religiosa. O Céu revela-se infinito, transcendente. É por excelência o ganz andere diante do qual o homem e seu meio ambiente pouco representam. A transcendência revela-se pela simples tomada de consciência da altura infinita. ${ }^{20}$

Em east e west ocorre o eco dos fonemas /s/ e /t/ cuja sonoridade forma uma rima interna para sugerir a intensidade da escuridão no horizonte, e a expressão black mass simboliza a noite, que, ao invadir a paisagem com tonalidade escuras, representa uma pintura na qual os contornos da vegetação se perdem, assim como se perdem os limites entre o real e o imaginário nos pensamentos do narrador. Desse modo, "O espaço aparece então ao poeta como sujeito do verbo desenvolver-se, do verbo crescer. Desde que um espaço seja um valor - e haverá valor maior que a intimidade? - ele crescerá" ${ }^{21}$

O silêncio e a calmaria da noite propiciam um momento de reflexão e introspecção, onde germinam novas percepções sobre a natureza, a vida e a humanidade. Embora a acepção da palavra noite esteja relacionada à escuridão e

\footnotetext{
${ }^{19}$ Jean Y Tadié, Le récit poétique, 1978, p. 4.

${ }^{20}$ Mircea Eliade, Aspectos do mito, 1992, p. 60

${ }^{21}$ Gaston Bachelard, A poética do espaço, 2003, p. 206.
} 
ao inconsciente, no conto, a noite tem o sentido metafórico de clareza de ideias, de luz da razão. Assim,

A noite simboliza o tempo das gestações, das germinações, das conspirações, que vão desabrochar em pleno dia como manifestação da vida. Ela é rica em todas as virtualidades da existência. Mas entrar na noite é voltar ao indeterminado, onde se misturam pesadelos e monstros, as ideias negras. Ela é a imagem do inconsciente e, no sono da noite, o inconsciente se libera. Como todo símbolo, a noite apresenta um duplo aspecto, o das trevas onde fermenta o vir a ser, e o da preparação do dia, de onde brotará a luz do dia. ${ }^{22}$

No final do segundo parágrafo, a frase and a star looking down through every cranny exprime a ideia de que no céu há uma estrela que, ao olhar para baixo, reflete sua luz por todas as direções. O valor polissêmico da palavra estrela refere-se ao astro propriamente dito, à luminosidade rompendo a escuridão e denota proteção ao evocar a luz divina. Nesse sentido, a estrela representa uma metáfora do sagrado, pois, ainda que o homem viva nas trevas cercado de maldade e egoísmo, há uma luz maior velando por todos.

Esse momento de reflexão do narrador é interrompido por imagens fantasmagóricas de formas humanas intangíveis. Essas imagens representam a iniquidade humana, cuja pretensão é invadir seus devaneios para trazê-lo à realidade. Entretanto, ele prefere continuar absorto nos encantos da noite para fugir do mundo real e de suas limitações.

A reverência à noite e a atmosfera onírica permitem ao narrador vivenciar uma experiência mítica, na medida em que

"Viver" os mitos implica, portanto, uma experiência verdadeiramente religiosa, visto que se distingue da experiência vulgar da vida cotidiana. [....; deixa-se de existir no mundo de todos os dias e penetra-se num mundo transfigurado, auroral, impregnado da presença dos Seres Sobrenaturais. ${ }^{23}$

No quarto parágrafo, o narrador faz uma comparação entre o homem e os gafanhotos para demonstrar a sabedoria da natureza. Ao contrário da confusão das vozes humanas, os gafanhotos são mais sábios, por se expressarem de forma

\footnotetext{
22 Jean Chevalier e Alain Gheerbrant, Dicionário de Símbolos, 1997, p. 639 a 640.

${ }^{23}$ Mircea Eliade, Aspectos do mito, 1963, p. 23.
} 
harmoniosa. Em sleep, sleep, sleep, a sequência dos verbos cria uma onomatopeia que, através da repetição e da sonoridade, representa uma canção de ninar para o narrador. A cadência da melodia dos gafanhotos e a escuridão o convidam a divagar por um mundo de sonhos onde o imaginário se manifesta livremente.

No desfecho do conto, o excerto It was a man's voice that broke the necromancer's spell manifesta a insatisfação do protagonista diante da mediocridade humana, ao exprimir a ideia de que o homem se afasta do sagrado por meio de suas ações. Ao referir-se à necromancia, o narrador estabelece uma ligação entre o mundo real e o mundo espiritual.

Na concepção do narrador, os homens não são capazes de falar de Cristo por terem quebrado o vínculo com o sagrado, já que pregam as palavras divinas esvaziadas de religiosidade, pois os valores mundanos se sobrepõem aos espirituais.

No excerto What does he know of Christ? Shall I ask a young fool who was born yesterday and will die tomorrow to tell me things of Christ? o narrador demonstra sua indignação diante da pretensão do homem que fala de Cristo como se o conhecesse através da bíblia, quando, para ele, é necessário buscar na natureza a transcendência das limitações humanas, pois "[...] toda a Natureza é suscetível de revelar-se como sacralidade cósmica". ${ }^{24}$

Quando o narrador diz que preferia perguntar às estrelas sobre Cristo porque elas o viram, há uma intertextualidade com o Evangelho de Mateus, cuja passagem bíblica refere-se à estrela mais brilhante já vista no céu, a estrela de Belém, que surgiu para anunciar o nascimento de Jesus e guiar os Reis Magos até o lugar onde o menino Jesus, sua mãe, Maria, e José estavam. ${ }^{25}$

Assim, a referência ao mito revela-se no questionamento do protagonista sobre a capacidade do homem mortal de conhecer Cristo, em

\footnotetext{
${ }^{24}$ Mircea Eliade, O Sagrado e o Profano, 1992, p. 13.

${ }^{25}$ Bíblia sagrada: contendo o antigo e o novo testamento, Mateus, 2, 1-12, 1966, p. 2545-2546.
} 
oposição às estrelas que já O viram e que continuarão a existir quando o homem não estiver mais na Terra. Para ele, somente a comunhão entre o homem e a natureza pode aproximá-lo do sagrado, uma vez que a divindade se comunica com o homem por meio da natureza, pois "O Céu revela, por seu próprio modo de ser, a transcendência, a força, a eternidade. Ele existe de uma maneira absoluta, pois é elevado, infinito, eterno, poderoso" ${ }^{26}$

Corrompido pelos prazeres mundanos e movido pela ambição, o homem não mede esforços para dominar a natureza, quando, na visão do narrador, deveria sentir-se como parte dela. Nesse sentido, ele critica a hipocrisia das lições bíblicas, a diferença entre aparência e essência e as atitudes humanas de profanação do sagrado.

\section{Aspectos da prosa em $A$ Reflection}

O conto A Reflection foi escrito em novembro de 1899 e publicado na obra Kate Chopin and Her Creole Stories (1932), por Daniel R. Rankin. Posteriormente, foi republicado na obra The Complete Works of Kate Chopin (1969), por Per Seyersted. ${ }^{27}$

O narrador personagem apresenta suas reflexões a respeito de uma procissão.

A imprecisão das personagens, que, assim como o narrador, não possuem nomes, e a data em que o conto foi escrito possivelmente fazem alusão à sociedade estadunidense fin de siècle, que vivenciou um período de profundas transformações sociais pelo advento da urbanização e do avanço tecnológico, que acarretaram pessimismo e incertezas.

\footnotetext{
${ }^{26}$ Mircea Eliade, O Sagrado e o Profano, 1992, p. 60.

${ }^{27}$ Per Seyersted, The Complete Works of Kate Chopin, 1988, p. 1028.
} 
O tempo da narrativa é o presente e a passagem do tempo é medida pela passagem da procissão.

No que tange ao cenário do conto, trata-se de um espaço público onde uma multidão caminha desordenadamente.

O título evidencia o olhar crítico do narrador sobre a marcha caótica de indivíduos que acompanham uma procissão e as impressões reflexivas sobre a individualidade humana. É possível observar o aspecto irônico do enredo, uma vez que o conto é intitulado como o ato de refletir e trata justamente da falta de reflexão do homem, sobretudo porque ele segue o fluxo da multidão sem demonstrar nenhum tipo de posicionamento crítico.

\section{O viés poético em $A$ Reflection}

No primeiro parágrafo, o narrador revela sua perplexidade diante da maneira como algumas pessoas mostram-se indiferentes às transformações sociais, à passagem do tempo e às indagações sobre a vida. Para ele, esses indivíduos são fortunate beings que, ao invés de contemplar e questionar a procissão em movimento, preferem segui-la sem saber para onde irão.

A expressão vital and responsive energy exprime um oximoro na medida em que simboliza ausência de energia vital ao referir-se à passividade com que as pessoas seguem a procissão, o que é enfatizado pela recorrência da forma negativa dos verbos que aludem à ideia de indolência e à falta de posicionamento crítico diante das circunstâncias da vida.

Ao refletir sobre a atitude passiva e receptiva dos indivíduos, o narrador imprime um olhar crítico sobre a posição inquestionável com que o homem segue o ritmo das multidões, porém utiliza adjetivos que denotam positividade como vital and responsive energy, motive power e fortunate beings. Nesse sentido, ocorre 
a antítese das ideias do narrador, que qualifica atitudes que considera contrárias às suas convicções.

A aproximação de ideias contrárias com fundamento crítico é recorrente no enredo e configura-se através de imagens opostas, pois

Se no jogo texto/contexto, a composição da atitude irônica pode desdobrarse em mais de uma direção, por outro lado, a relação no interior do texto poético resulta, geralmente, da incongruência ou oposição dos vocábulos e imagens, pela inclusão de impulsos opostos e complementares. ${ }^{28}$

No excerto They are fortunate beings. They do not need to apprehend the significance of things. They do not grow weary nor miss step, há um paralelismo sonoro com a repetição do pronome pessoal they no início das frases, cuja estrutura reitera e acentua a ideia de que os seres afortunados são pessoas alheias aos significados profundos da vida, pois "o paralelismo dos sons engendra o paralelismo das significações"29. Contudo, o paralelismo engendra a ironia da autora quanto às relações humanas, marcadas pela indiferença e pelo egoísmo. Assim, observa-se a estratégia literária marcada por elementos poéticos cujas implicações denotam o viés de crítica social presente nas narrativas chopinianas.

Além disso, as expressões miss step, fall out of rank e sink by the wayside representam a metáfora do sentimento de inadequação social do narrador, que, através de um "mergulho" na sua interioridade, nega as convenções sociais ao "perder o passo" da procissão e ao sentir-se "cansado" da condição humana que não muda, apesar da passagem do tempo, das inovações tecnológicas e do progresso científico.

A alternância entre orações afirmativas e orações negativas denota a indignação do narrador diante da estagnação do homem e insensatez de seguir um caminho seguido pela maioria. Tal estratégia discursiva assinala, mais uma vez, o viés crítico presente no enredo em relação à sociedade americana do século XIX, sociedade essa marcada por profundas mudanças culturais, econômicas e

\footnotetext{
${ }^{28}$ Rita Bittencourt, Poesia e ironia: aproximações, 2006, p. 89.

${ }^{29}$ Maurice J. Lefebve, Estrutura do discurso da poesia e da narrativa, 1980, p. 117.
} 
sociais, principalmente sob a perspectiva da industrialização e do avanço tecnológico. Esse ritmo social acompanha o ritmo da procissão do conto. É interessante observar a metonímia que se constitui em relação à marcha de homens que caminham na procissão, uma vez que "ao produzir-se a metonímia, ocorre uma concentração semântica em um dado termo: este arca com o significado de outro com o qual guarda alguma relação de dependência ou de causalidade" ${ }^{\prime 30}$. Nesse prisma, a procissão representa a metonímia da concentração humana em um grupo social que organiza-se de uma forma individualista, evocando a ideia do homem imerso em uma marcha cujo "ritmo louco" não lhe permite observar nada além de seus próprios interesses.

Em It not only enables them to keep abreast of the times, o advérbio abreast tem um duplo sentido no enredo, pois figura a ideia da procissão ao formar uma imagem de pessoas que estão próximas e caminham em uma mesma direção, além de demonstrar a preocupação do homem com as banalidades da vida cotidiana, que busca estar a par do tempo e não se aprofunda em algo que possa transcender a realidade.

No segundo parágrafo, a frase exclamativa expressa a ironia do narrador, que não se sente excluído por não acompanhar a procissão, uma vez que ele percebe que a beleza das cores da passagem da multidão é revestida de indiferença e hipocrisia.

Considerando que "O verso, a frase ritmo, evoca, ressuscita, desperta, recria" ${ }^{31}$, a imagem poética em the majestic rhythm of the spheres evoca a grandiosidade divina e o equilíbrio da movimentação dos planetas. Em contrapartida, a expressão ever-pressing multitude recria o ritmo apressado da vida em sociedade. Nesse sentido, o paralelismo entre as duas frases simboliza a desordem causada pelo sentimento de urgência nas atitudes humanas e o consequente desequilíbrio das relações sociais.

\footnotetext{
${ }^{30}$ Alfredo Bosi, O ser e o tempo da poesia, 1977, p. 212.

31 Octavio Paz, O arco e a lira, 1982, p. 132.
} 
Ao contemplar o fluxo de pessoas seguindo a procissão, o narrador observa a incoerência do homem que, apesar de estar presente na multidão, está, ao mesmo tempo, ausente a ponto de não perceber o mundo ao seu redor. Nesse sentido, a reflexão do narrador exprime a ausência de sentido da vida daqueles que caminham na procissão, uma vez que

viver as coisas, e a sua presença, é viver ao mesmo tempo o problema dessa presença: toda manifestação vivida do ser se confunde com a interrogação que a seu propósito fazemos. ${ }^{32}$

O narrador articula a beleza da procissão com a invisibilidade do sofrimento daqueles que se encontram aos pés da multidão por meio do paradoxo que contrapõe os adjetivos fantastic, brilliant e beautiful à ideia expressa na frase What matter if souls and bodies are failing beneath the feet of the ever-pressing multitude! Logo, é possível observar um jogo semântico entre movimento e estagnação, uma vez que a procissão é formada por pessoas que caminham a esmo e o fluxo contínuo da caminhada não corresponde ao dinamismo das ideias que, do ponto de vista do narrador, estão cristalizadas pelo senso comum. Dessa forma, o tom irônico do enredo "[...] se dá no cerne mesmo da linguagem, resultado do confronto entre a atitude lírica e a intenção crítica, na busca de possibilidades internas de coexistência e de inter-relação" ${ }^{33}$. Considerando a ambiguidade como uma das características da linguagem poética, a locução adjetiva God's orchestra apresenta um duplo sentido no enredo, sobretudo porque "o poema transcende a linguagem" e "Nascido da palavra, o poema desemboca em algo que a ultrapassa"34.

A construção poética em Its discordant clashes sweep upward in one harmonious tone that blends with the music of other worlds evidencia a aproximação entre o verbo clashes e o adjetivo harmonious. Esse oximoro é a representação do olhar divino sobre as relações sociais conflituosas, pois, embora a discórdia ressoe entre os homens, ainda assim, todos são regidos pela "orquestra

\footnotetext{
${ }^{32}$ Maurice J. Lefebve, Estrutura do discurso da poesia e da narrativa, 1980, p. 121, grifo do autor.

${ }^{33}$ Rita Bittencourt, Poesia e ironia: aproximações, 2006, p. 87.

${ }^{34}$ Octavio Paz, O arco e a lira, 1982, p. 135.
} 
de Deus". Além disso, o campo semântico formado pelas palavras tone, music e orchestra alude aos cânticos que acompanham a procissão, enquanto os vocábulos other worlds e God's orchestra associam-se ao divino. A partir dessa imagem poética de música sagrada, o narrador personagem enfatiza o paradoxo entre a harmonia dos cânticos religiosos e a desarmonia das relações sociais, e tal comparação é enviesada de ironia, visto que

pressupõe a ironia como "espelho da realidade", ainda que seja de uma realidade aos pedaços, e que este "espelhamento" aconteça de viés, abrindo-se a ambigüidades [sic] e apostando em intervenções críticas mínimas, em circunstâncias que podem envolver formas variadas de criatividade artística. ${ }^{35}$

Assim, a imagem poética em God's orchestra expressa a indignação do protagonista em relação ao descompasso do homem na "orquestra divina", pois "a imagem é um recurso desesperado contra o silêncio que nos invade cada vez que tentamos exprimir a terrível experiência do que nos rodeia e de nós mesmos"36.

No terceiro parágrafo, o narrador compara o movimento da energia humana na procissão com as estrelas e, de uma forma metafórica, exprime a ideia de que, para a humanidade, as questões materiais são mais relevantes do que as espirituais.

$\mathrm{Na}$ expressão the palpitating earth and the things growing thereon, o narrador faz uma referência à grandiosidade da criação divina para ironizar a prepotência do homem que acompanha a procissão e se considera superior à própria natureza.

Por meio do discurso irônico, o narrador expressa o seu contentamento por não fazer parte da procissão, pois sente-se mais próximo da natureza do que de seus pares e busca transcender a ilusão que cega os indivíduos. Desse modo, na frase Oh! I could weep at being left by the wayside; left with the grass and the clouds and a few dumb animals, a interjeição e o uso do verbo modal could no

\footnotetext{
${ }^{35}$ Rita Bittencourt, Poesia e ironia: aproximações, 2006, p. 87.

${ }^{36}$ Octavio Paz, O arco e a lira, 1982, p. 135.
} 
passado representam o tom irônico do narrador ao expressar que prefere a solidão e a exclusão social ao invés de seguir o caminho medíocre escolhido pela maioria.

O narrador mostra sua resignação diante dos "símbolos da imutabilidade da vida" representados pela sociedade vazia de princípios e pela natureza inalterável da condição humana. Através da negação do social, ele posiciona-se com uma certa perspicácia e rebeldia perante o movimento caótico da procissão, que se caracteriza pelas expressões crushing feet, clashing discords, ruthless hands e stifling breath, que reforçam a imagem poética do conto sintetizada pelo individualismo e pela hipocrisia.

A sinestesia em crushing feet, ruthless hands e stifling breath expressa a hostilidade das relações humanas, uma vez que a procissão é formada por homens que caminham com "pés esmagadores", simbolizando a competitividade e ausência de compaixão entre os indivíduos; as "mãos" que poderiam socorrer são "implacáveis" e a "respiração ofegante" figura o esgotamento das relações sociais e a vida esvaziada de sentido daqueles que seguem a procissão.

Na frase I could not hear the rhythm of the march, o verbo "ouvir" tem um sentido metafórico, pois revela que, diferentemente dos "seres afortunados", o narrador não foi corrompido pelos ideais que regem a procissão, ideais esses que contrariam os seus princípios.

A interjeição e a metáfora presentes na expressão Salve! ye dumb hearts exprimem a ironia do narrador diante da insensibilidade dos indivíduos de "corações mudos" para acentuar a incoerência entre aparência e essência na esfera social.

A frase que conclui o conto reflete a escolha do narrador por permanecer alheio à procissão, pois o lugar de espectador o mantém fora do círculo social. A relação entre o caminho seguido por todos e a beira da estrada revela seu 
posicionamento crítico e reitera a ideia da reflexão, pois sugere ao leitor que é melhor esperar à beira da estrada do que ser esmagado pela procissão.

Assim, é possível conceber a procissão como uma alegoria das relações humanas permeadas por conflitos e hipocrisia. Somente pode-se engendrar tal alegoria a partir do ponto de vista crítico do narrador, pois, ao refletir a respeito da procissão sob a perspectiva de quem está do lado de fora, ele observa aquilo que a multidão não pode ou não quer ver.

\section{Considerações finais}

Através das análises propostas neste artigo, pode-se observar o viés crítico da prosa poética chopiniana através do discurso irônico para subverter valores e de imagens poéticas construídas no enredo, pois tais imagens "[...] dizem algo sobre o mundo e sobre nós mesmos, e que esse algo, ainda que pareça um disparate, nos revela de fato o que somos"37.

Assim, no conto The Night Came Slowly, o narrador contempla a noite como forma de compreensão de suas indagações a respeito da condição humana, e a comunhão com a natureza lhe traz as respostas que não encontrou na sociedade ou nos livros, pois esta experiência transcende os valores mundanos.

Em A Reflection, o ritual representado pela procissão assinala a mediocridade da natureza humana, uma vez que esta é constituída por indivíduos que vestem uma máscara social através da qual as aparências escondem a essência marcadamente hipócrita das convenções sociais, que caminham em um ritmo desarmônico ao da "orquestra de Deus".

Considerando que "a poesia tem uma felicidade que lhe é própria, qualquer que seja o drama que ela seja levada a ilustrar"38, conclui-se, portanto, que a prosa

\footnotetext{
37 Octavio Paz, O arco e a lira, 1982, p.131.

${ }^{38}$ Gaston Bachelard, A poética do espaço, 2003, p.192.
} 
poética de Kate Chopin denota uma escrita profundamente crítica, que, por meio de imagens liricamente encarnadas, prima por tratar de questões metafísicas e atemporais, sobretudo para desvelar a verdadeira face da natureza humana.

\section{Referências}

BACHELARD, Gaston. A poética do espaço. Trad. Antonio de Pádua Danesi. São Paulo: Martins Fontes, 2003.

BENDER, Bert. "Kate Chopin's Lyrical Short Stories" In Studies in Short Fiction. Newberry, S. C. Vol. 11, Ed 3 (Summer1974): 257.

BÍBLIA. Português. Bíblia sagrada: contendo o antigo e o novo testamento. Tradução de João Ferreira de Almeida. Rio de Janeiro: Sociedade Bíblica do Brasil, 1966. p. 2545-2546.

BITTENCOURT, Rita Lenira de Freitas. Poesia e ironia: aproximações. In Poesia: passagens e impasses. Florianópolis, v. 6, n. 8/9, p. 1-8 2006. Disponível em: $<$ https://periodicos.ufsc.br/index.php/nelic/article/view/1576/1309>. Acesso em: 16 jan. 2019.

BOSI, Alfredo. O ser e o tempo da poesia. São Paulo: Cultrix, 1977.

CHEVALIER, Jean \& GHEERBRANT, Alain. Dicionário de Símbolos. Rio de Janeiro: J. Olympio, 1997.

CHOPIN, Kate. "The Night Came Slowly". In: SEYERSTED, Per (ed.). The Complete Works of Kate Chopin. Baton Rouge: Louisiana State University Press, 1988, p. 366 (Southern Literary Studies).

CHOPIN, Kate. "A Reflection". In: SEYERSTED, Per (ed.). The Complete Works of Kate Chopin. Baton Rouge: Louisiana State University Press, 1988, p. 622 (Southern Literary Studies). 
ELIADE, Mircea. Aspectos do mito. Trad. Manuela Torres. Lisboa: Edições 70, 1963.

ELIADE, Mircea. O Sagrado e o Profano. Trad. Rogério Fernandes. São Paulo: Martins Fontes, 1992.

KOLOSKI, Bernard (ed.). Awakenings. The Story of the Kate Chopin Revival. Baton Rouge (LA): Louisiana State University Press, 2009 (Southern Literary Studies).

LEFEBVE, M.-J. Estrutura do discurso da poesia e da narrativa. Trad. José Carlos Seabra Pereira. Coimbra: Almedina, 1980.

MOISÉS, Massaud. Dicionário de termos literários. São Paulo: Cultrix, 1974.

PAZ, Octavio. O arco e a Lira. Rio de Janeiro: Nova Fronteira, 1982.

PETRY, Alice Hall (ed.). Critical Essays on Kate Chopin. New York: G. K. Hall \& Co., 1996 (Critical Essays on American Literature).

RANKIN, Daniel S. Kate Chopin and her Creole Stories. Philadelphia (PA):

University of Pennsylvania Press, 1932.

SEYERSTED, Per (ed.). The Complete Works of Kate Chopin. Baton Rouge:

Louisiana State University Press, 1988, (Southern Literary Studies).

SEYERSTED, Per (ed.). Kate Chopin. A Critical Biography. Baton Rouge (LA):

Louisiana State University Press, 1980.

TADIÉ, Jean Y. Le récit poétique. Paris: PUF, 1978. (Introdução: trad. Ana Luiza Camarani, p. 1055-1056).

VALÉRY, Paul. Variedades. Tradução Maiza Martins de Siqueira. São Paulo Iluminuras, 2007. 


\section{Referência para citação deste artigo}

FINATTI, Rosemary. A Prosa Poética de Kate Chopin: imagens líricas da noite e o descompasso do homem na orquestra de Deus. Revista PHILIA | Filosofia, Literatura \& Arte, Porto Alegre, volume 1, número 2, p. 484 - 504, outubro de 2019. 